\title{
Relacions de gènere en les parelles mixtes residents a les àrees rurals $i$ urbanes del camp de tarragona. Un estudi de dones i homes catalans aparellats amb persones estrangeres
}

Institut Català de les Dones U-43/10

Jordi Roca Girona (investigador principal), Claudia Anleu Hernández (investigadora), Mercedes González Minguillón (investigadora becada)

Des de l'any 2006, i amb diferents equips, hem estat treballant sobre parelles mixtes o matrimonis binacionals en sengles projectes del Plan Nacional de $\mathrm{I}+\mathrm{D}+\mathrm{I}:^{1}$ primer amb matrimonis entre homes espanyols i dones estrangeres, els majoritaris entre les parelles mixtes espanyoles, i després incorporant també les unions de dones espanyoles amb homes estrangers. Per bé que ambdues recerques han estat de caire qualitatiu, sempre hem pres en consideració amb finalitats analítiques i de plantejament el conjunt de l'Estat. Teníem interès, doncs, a dur a terme una recerca més modesta quant al territori a abastar que ens permetés així mateix focalitzar l’atenció en qüestions més específiques i localitzades. El projecte concedit per l'Institut Català de les Dones, que hem dut a terme en el període 2010-2011, ens ha donat l'oportunitat de realitzar-la.

Lobjectiu general del projecte ha estat explorar les relacions de gènere, les relacions amb les famílies d'orientació i les relacions amb els fills que es donen en les parelles mixtes residents al Camp de Tarragona. El context estadístic del fenomen es mostra clarament en la taula següent:

\footnotetext{
1. "Amor importado, migrantes por amor: la constitución de parejas entre españoles y mujeres de América latina y de Europa del Este en el marco de la transformación actual del sistema de género en España", Proyectos de Investigación Científica y Desarrollo Tecnológico; Programa: Acción Estratégica sobre Fomento de Igualdad de Oportunidades entre Mujeres y Hombres; Plan Nacional de I+D+I (2004-2007), Ministerio de Trabajo y Asuntos Sociales, Instituto de la Mujer: 2006-2008. "Amores transnacionales: constitución y desarrollo de parejas mixtas en España". Plan Nacional de I+D+I (2008-2011), Ministerio de Ciencia e Innovación (CSO2009-10187): 2010-2012.
} 
Matrimonis mixtos: Espanya, Catalunya, Tarragona, Camp de Tarragona (2009)

\begin{tabular}{|l|c|c|c|}
\hline Territori & $\begin{array}{c}\text { Home autòcton } \\
\text { amb dona } \\
\text { estrangera }\end{array}$ & $\begin{array}{c}\text { Dona autòctona amb } \\
\text { home estranger }\end{array}$ & $\begin{array}{c}\text { Total } \\
\text { matrimonis } \\
\text { mixtos }\end{array}$ \\
\hline Espanya & 17.327 & 11.955 & 29.282 \\
\hline Catalunya & 3.964 & 2.032 & 5.996 \\
\hline Barcelona & 2.926 & 1.446 & 4.372 \\
\hline Tarragona & 482 & 249 & 731 \\
\hline Girona & 327 & 218 & 545 \\
\hline Lleida & 229 & 118 & 347 \\
\hline $\begin{array}{l}\text { Camp de } \\
\text { Tarragona }\end{array}$ & 329 & 180 & 509 \\
\hline
\end{tabular}

Font: Idescat (www.idescat.cat) i INE (www.ine.es), consultades el 26/07/2011. Elaboració pròpia.

Al llarg de la recerca es va realitzar un total de 33 entrevistes - 16 entrevistes conjuntes amb profunditat a parelles mixtes, 2 entrevistes focals a llevadores dels Assir (Atenció a la Salut Sexual i Reproductiva) de Tarragona i Reus i 15 entrevistes a diferents agents socials pertanyents als àmbits de l'educació, la sanitat, la llengua, la immigració i l'associacionisme cultural immigrant—, amb un total de 67 informants.

Els principals resultats que hem assolit els podem agrupar en els tres grans apartats que conformaven l'objectiu general del projecte i en dues consideracions de caire conclusiu.

Pel que fa a les relacions de gènere característiques de les anomenades parelles mixtes, hem constatat la importància que es concedeix a l'experiència de relacions amb parelles anteriors i a l'educació i als valors culturals del país d'origen de cada membre de la parella com a elements influents en la relació de parella. Tanmateix, el pes i la presència de la cultura del cònjuge estranger és modulada per la valoració que sén fa en la cultura de destí, la qual cosa pot arribar a suposar-ne la renúncia. Fins i tot en alguns casos la recerca d'una unió mixta es presenta com una estratègia de fugida de les relacions de gènere característiques de la cultura d'origen. Malgrat això, val a dir que les dades que vam obtenir ens van regalar algunes sorpreses no previstes. És així que, pel que 
fa a l'assumpció de les tasques domèstiques, la responsabilitat de la dona esdevé gairebé universal, amb independència de la nacionalitat i del fet que sigui la dona el membre estranger de la parella — un aspecte que les nostres hipòtesis sí que contemplaven - o no, la qual cosa no esperàvem. En el cas, doncs, de les dones catalanes casades amb homes estrangers, podem afirmar que es dóna una certa involució en les relacions de gènere, la qual cosa sovint és justificada per les mateixes protagonistes en termes d'una mena d'economia de bescanvi: afecte i relacions d'estima a canvi de nullla o poca participació masculina en les tasques domèstiques. En aquest punt encara és destacable també el fet que la majoria d'esposes estrangeres amb estudis mitjançant el matrimoni amb un home català veuen frenada, si més no inicialment, la seva dinàmica laboral a causa de la qüestió sovint complicada de l'homologació de títols. La llengua de comunicació de la parella, finalment, acostuma a ser aquella amb la qual es van comunicar en conèixer-se.

Quant a les relacions amb les famílies d'orientació, podem destacar l'ampli espectre de formes d'acolliment del cònjuge estranger. En qualsevol cas, hem constatat, com també ho han fet altres estudis realitzats en entorns diferents, que és més rellevant la classe social del cònjuge estranger que no pas l'idioma en el caire assolit pel procés d'acolliment, i que tot i la importància del prejudicis ètnics i els estereotips nacionals, el temps — l l'arribada dels fills que sovint hi va associada - acostuma a normalitzar les relacions, tot i que en entorns rurals les reaccions poden assolir un grau més elevat de rebuig. Quan el cònjuge estranger és l'home es constata un major desarrelament amb relació a la família d'orientació que no pas quan és la dona la part migrant de la parella.

Les relacions amb fills i filles constituí el tercer gran apartat d'interès de la recerca. L'aparició dels fills, sempre rellevant en qualsevol parella, n'esdevé encara més en el cas d'una parella mixta, pel fet que legitima i consolida una relació sovint mirada amb recel, i perquè planteja qüestions força interessants $\mathrm{i}$ importants com ara el fet de com es transmet la doble referència cultural als fills — nacionalitat, nom, llengua, religió-. Les famílies mixtes posseeixen un alt grau de bilingüisme i trilingüisme, i són cabdals en aquest punt elements com ara la valoració de l'idioma del membre estranger de la parella, el nivell de competència lingüística d'ambdós membres de la parella a l'hora de conèixer-se així com el nivell cultural i socioeconòmic dels membres de la parella. Els fills, d'altra banda, faciliten sovint la socialització de la mare estrangera amb poc 
temps d'estada a la societat de destí o amb poca xarxa social i fan de mitjancers culturals amb les famílies d'orientació de la parella, alhora que posen sobre la taula qüestions com ara la participació en la criança de la família del cònjuge estranger.

Més enllà d'aquests aspectes concrets centrats en els tres grans punts que hem assenyalat, la recerca ens ha mostrat un seguit d'elements rellevants d'entre els quals en volem destacar dos. En primer lloc, com en l'estratègia discursiva dels informants sobre les relacions de gènere en la parella susen i manipulen dimensions personals i culturals-nacionals ensems. És a dir, que sapellla indistintament a elements de la personalitat pròpia i d'altri com als estereotips nacionals d'un i altre. En l'àmbit de les pràctiques, al seu torn, és destacable, com ja hem fet, la ubicació de les dones com a responsables de l'àmbit domèstic i reproductiu, tant si són la part estrangera com autòctona de la parella. En segon lloc, és remarcable així mateix la importància dels fills en aquestes unions com a detonants per fer aflorar la dimensió intercultural característica de les parelles mixtes.

Aquestes consideracions de caire conclusiu constitueixen, sens dubte, alguns eixos problemàtics de les anomenades parelles i famílies mixtes que caldria aprofundir en el futur.

Jordi Roca Girona 